\title{
Perception of Lecturer on Intercultural Competence and Culture Teaching Time (Case
}

\author{
Enkeleda Jata PhD Cand. \\ European University of Tirana, Albania, \\ enki_jata@yahoo.it
}

\begin{abstract}
Of all the changes that have affected language teaching theory and method in recent years, the greatest may be the transformation in the role of culture. This change reflects a broader transformation in the way that culture itself is understood. Culture is listed nowadays the fifth element of learning the foreign language. However, the perception of the professors to include culture as part of their teaching is still vain. This article involves ten English professors to understand their opinions regarding culture, and why they cannot develop intercultural competence during their classes. How culture is served in the classrooms depends from the professors opinions. This research was conducted based on the need to investigate culture teaching in English language in Albania. The data collected show that all the professors perform their lessons based on a curriculum which is limited regarding the culture aspects.
\end{abstract}

Keywords: Perception, lecturer, intercultural competence, culture, teaching time

\section{Introduction}

In the time that we are living and with the increase of people mobility, it is required to prepare students to communicate with individuals of different culture. The idea of teaching culture in foreign language education has been discussed a lot among scholars and academic people, but without making it part of the curricula. Still, a lot of language professors think that culture is part of anthropology and not to be taught by the foreign language teachers. Even though during the foreign language classes are treated different aspect of culture such as: everyday life, information regarding English-speaking countries, but they do not help to develop intercultural competence. "Culture and communication are inseparable because culture not only dictates who talks to whom, about what, and how the communication proceeds, it also helps to determine how people encode messages, the meaning they have for messages, and the conditions and circumstances under which various messages may or may not be sent, noticed or interpreted... Culture is the foundation of communication"(Samovar, Porter, \& Jain, 1981) From this you can understand that culture is closely interrelated with language. It is important to keep in mind that culture is not something static but it is process that accompanies us during our life and it helps to give meaning to the words.

A lot of studies have been done regarding the importance of culture and the role of foreign language teachers. One of the most important studies is that of Sercu's, an international investigation on foreign language teachers and intercultural competence. This article is focused to find out how much time do the teachers in Albania dedicate to the teaching of culture and language competence and what the objectives of the professors are while teaching a foreign language. By understanding what the professors think will help to see where can be implement any changes in the curriculum.

\section{Methodology}

The methodology of the research discussed is a qualitative one. The questionnaire that I have used is adapted by Lies Sercu(An international investigation: Section 3: You as a teacher). It was completed by ten professors who taught English as foreign language to the students at University in Albania. All the participants have teaching experience more than five years. They were asked to rank according to the importance the objectives in order to understand how much time they dedicated to culture. From the data collected it is quite clear that the linguistic competences are the main important objectives of teaching a foreign language. 


\section{Analysis of Perception of the Lecturer}

My purpose in the study was to learn about professors' perception of culture in order to understand whether they are willing to teach culture as general knowledge (facts) or as process to help students to acquire the adequate skills to interpret, analyze and compare on their own. Ten professors were given eight potential objectives to list them according to their importance and the one less important. These eight potential objectives are divided in culture learning objectives, language learning objectives, general skills/language skills.

\section{Culture learning objectives}

(1) Promote pupils' familiarity with the culture, and with the civilisation of the countries where the language, which they are learning, is spoken.

(2) Promote the acquisition of an open mind and a positive disposition towards unfamiliar cultures.

(3) Assist pupils to develop a better understanding of their own identity and culture.

\section{Language learning objectives}

(4) Assist pupils to acquire a level of proficiency in the foreign language that will allow them to read literary works in that foreign language.

(5) Enthuse pupils to learn foreign languages.

(6) Promote the acquisition of a level of proficiency in the foreign language that will allow the learners to use the foreign language for practical purposes.

\section{General skills/language skills learning objectives}

(7) Assist pupils to acquire the skills that will be useful in other subject areas in life (such as memorise, put into words, formulate accurately, give a presentation, etc.).

(8) Promote the acquisition of learning skills that will be useful for learning other foreign languages.

\section{Table 1- Possible objectives of foreign language education}

$70 \%$ of the professors have chosen these two options. Both of these two options clearly show that linguistic competences are the most important ones.

4. Assist pupils to acquire a level of proficiency in the foreign language that will allow them to read literary works in that foreign language.

5. Assist pupils to acquire the skills that will be useful in other subject areas in life (such as memories, put into words, formulate accurately, give a presentation, etc.).

Of course the four skills: speaking, reading, writing, listening are crucial and we are not going to stop it, but it's important to address the fifth skill - culture. The problem is that the Albania students have difficulties in these aspects mentioned and that is the reason why the professors dedicate more time to linguistic competence; they prefer to help the students acquire the skills to be able to communicate in English language.

The objectives that were ranked last are:

3. Assist pupils to develop a better understanding of their own identity and culture.

8. Promote the acquisition of learning skills that will be useful for learning other foreign languages.

Both of these objectives are characterized as cultural and generals skills. Since both of them are ranked last by the professors it means these two aspects are not developed by the professor at the university. In fact, if professors do not 
help students by making a comparison of target and source culture, they won't be able to acquire the skills needed in order to increase their ability to communicate across cultures. It is the professors' responsibility to take the role of informant by giving information and asking them to show that they know it; to take the role of guide to engage students to make researchers and reach conclusions about cultural information.

\section{What do the professors understand with "teaching of culture" under the context of teaching a foreign language?}

The other part of the questionnaire has to do with the opinions of the professors about the "teaching of culture". In the questionnaire they were asked to rank nine possible culture-teaching objectives. They are divided in knowledge dimension, the attitudinal dimension and skills dimension. An estimation of $70 \%$ of professors consider teaching culture more in terms of passing knowledge regarding daily life or history, geography, etc.

\begin{tabular}{|l|}
\hline Knowledge dimension \\
\hline Provide information about the history, geography and political conditions of the foreign culture(s) (culture/Culture). \\
\hline Provide information about daily life and routines (culture). \\
\hline Provide information about shared values and beliefs (culture/Culture) \\
\hline Provide experiences with a rich variety of cultural expressions (literature, music, theatre, film, etc.) (Culture). \\
\hline Attitudinal dimension \\
\hline Develop attitudes of openness and tolerance towards other people and cultures. \\
\hline Skills dimension \\
\hline Promote reflection on cultural differences. \\
\hline Promote increased understanding of students' own culture (also knowledge of own culture/Culture). \\
\hline Promote the ability to empathize with people living in other cultures. \\
\hline Promote the ability to handle intercultural contact situations. \\
\hline
\end{tabular}

\section{Table 2.Possible culture teaching objectives}

From the answers of the professors we can see that the majority of them ranked first the objective about daily life and second most important objective ranked history, geography and political issues of a foreign culture.

1. Providing of information in relation to daily life.

2. Providing of information on history, geography and political issues of foreign culture.

3. The last ranked options are;

4. Promote the ability to empathize with people living in other cultures.

5. Promote the ability to handle intercultural contact situations.

This means that the professors are more focused on passing knowledge to the students regarding different fields of culture. The main reason why the professors are focused more on these two points is because they want to increase students' familiarity rather than developing intercultural competence. It is important to keep in mind that if students' memorize facts of the English-speaking country by heart, they are not going to develop intercultural skills. Students must be stimulated to conduct researches on different cultural topics and to discuss it in class among each other. Professors must give to students extra materials to read and to include culture on the exams, in these way students will be more motivated to conduct researchers on their own. By the help of professors, students must learn how to react appropriately in a social situation; describe a pattern in the culture; "explain" a pattern; predict how a pattern is likely to apply in a given situation etc. It is the professors' duty to increase the students' curiosity about the target culture and empathy toward its people. This can be done by using different techniques or activities such as: dialogs, role plays, simulations. 


\section{How do professors plan their teaching hours for teaching of language and teaching of culture}

This question is to find out the average allocation of the teaching time. To the professors they were given several options to choose which is shown on the graph below.

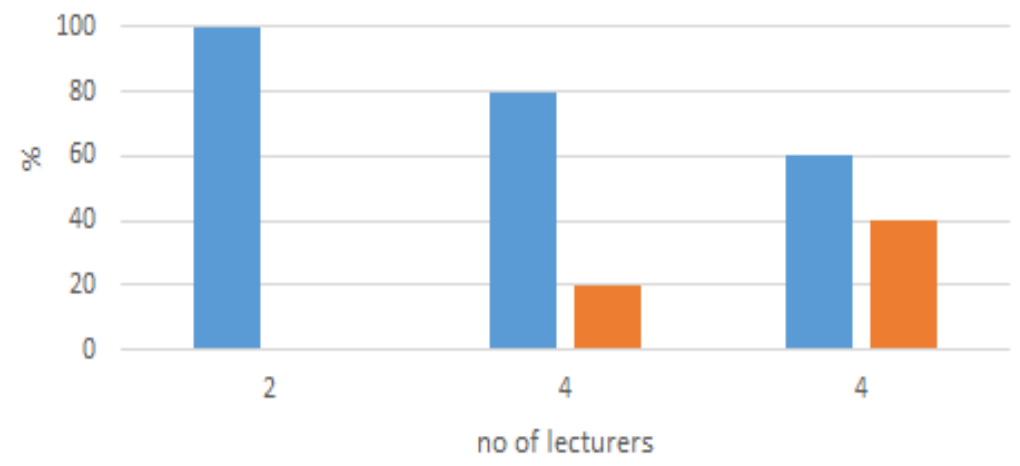

language teaching ucultur e teaching

From the graph it is clearly shown that the majority of professors are focused more on language teaching. The time they dedicated to culture varies between $20 \%-40 \%$. Two professors have chosen the option $100 \%$ language teaching- $0 \%$ culture teaching; while the other professors have chosen the options $80 \%$ language teaching $-20 \%$ culture teaching or $60 \%$ language teaching- $40 \%$ culture teaching. This means that they still hesitate to interrelate culture and language .The following question was if they have the feeling that they would have liked to plan more time for teaching of culture during the teaching classes of foreign language but they have not managed to achieve it. Most of them would like to dedicate more time to culture teaching but at certain extend. The last question of this section was an open question to give some reasons why they didn't dedicate much time to culture. They wrote different things why they couldn't dedicate more time to culture teaching some of them were:

- $\quad$ Course book restriction

- I I usually don't have problem managing my teaching plans but there are times that I have to teach the language mostly due to the lack of teaching time

- Another reason is that the Albania students encounter lots of difficulties at the English grammar and the examples introduced to them do not have culture elements between the lines.

- $\quad$ The curricula program is organized in modules and it does not include culture in it.

- I think students may not like learning the culture

- It is difficult to teach culture when they are not at a proficient level in English

Some of the problems they mention in teaching culture are:

1. The curriculum restriction, they have a curriculum to follow and since the hours are limited they don't have time to focus on culture aspects. Whenever they have free hours they would like to dedicate more time to the aspects where students encounter difficulties such as grammar or speaking.

2. Lack of time: Professors need to work extra hours in order to find materials to present to the students since the materials presented in the books are not enough.

3. Another reason presented is that in the beginner or intermediate level, teachers are more focused to develop students' ability to speak and to write the language in the appropriate grammatical way. 
4. Lack of students' interest to learn the culture of English-speaking countries. This may be related to the professors fear how to deal with students negative attitudes towards other cultures.

5.

\section{Conclusion}

The findings of this study show that professors are aware of the importance of culture in the classrooms, but do not integrate it in the syllabus because of the reasons mentioned before. I think it is important to teach language together with culture and are the professors who should lead the students towards the target culture by taking different roles in the classroom such as that of the informant; coach; co-researcher or guide. It is not difficult for students to learn the vocabulary or grammar of English language, the main difficulty is to be able to form sentence and to communicate within the culture context. Culture needs to be present even at the beginning level of learning a language. If they don't understand the culture of the language they are learning, it will be difficult to communicate or to choose the right words in the appropriate culture context. It is now professors' responsibility to teach the culture while teaching a foreign language and be constantly updated with the changes that occur over time. Teaching culture needs to be integrated in the curriculum of the foreign language.

\section{Reference}

[1] Alptekin, C. (2002). Towards intercultural communicative competence. ELT Journal

[2] Brown, A.V. (2009). Students' and teachers' perceptions of effective foreign language teaching: A comparison of ideals. The Modern Language Journal,

[3] Byram, M.(1989). Cultural Studies in Foreign Language Education: Multilingual Matters

[4] Corbett,J. (2003). An Intercultural approach to English Language Teaching: Multilingual Matters

[5] Cheryl,A. Hunter., Donna K.Pearson and A.Renne Gutierrez. Interculturalization and Teacher Education theory to practice

[6] Chisholm I.M.Preparing Teachers For Multicultural Classrooms. The Journal of Educational Issues of Language Minority Students.

[7] Damen, L. (1987). Culture Learning: the fifth dimension in the language classroom.

[8] Fang, Z. A review of research on teacher beliefs and practices. Educational Research,

[9] Kramsch,C.(1998). Language and Culture: Oxford University Press

[10] Lazar.I, Huber-Kriegler.M, Lussier.D, S.Matei.G, Peck.Ch, Developing and assessing intercultural communicative competence- $A$ guide for language teachers and teacher educators

[11] Lazar,I. (2003) Incorporating intercultural communicative competence in language teacher education; European Center for Modern Languages Council of Europe Publishing

[12] Moran R. P. (2001) Teaching Culture: Perspectives in Practice: The Electronic Journal for English as a Second Language

[13] Samovar, L., Porter, R. \& Jain, N. (1981).Understanding intercultural communication. Belmont, CA: Wadsworth.

[14] S, Saglam.,Ipek Kuru Gonen S. Teaching culture in the FL classroom: Teachers' perspectives, IJGE: International Journal of Global Education-2012, volume 1 issue 3

[15] Sercu, L. (2000). Acquiring intercultural communicative competence from textbooks. Leuven: Leuven University Press.

[16] Sercu, L. (2005). Foreign language teachers and intercultural competence: An international investigation. Clevedon: Cromwell Press.

[17] R. Michael Paige, Jorstad,H., Siaya,L., Klein,F,. Colby J. Culture Learning in Language Education: A Review of the literature 